\title{
NATUROPATHY SYSTEM - A COMPLIMENTARY AND ALTERNATIVE AID IN DENTISTRY - A REVIEW
}

Yatish Kumar Sanadhya1, Sanadhya Sudhanshu², Sorabh R Jain³, Nidhi Sharma4

\section{HOW TO CITE THIS ARTICLE:}

Yatish Kumar Sanadhya, Sanadhya Sudhanshu, Sorabh R Jain, Nidhi Sharma. "Naturopathy system - a complimentary and alternative aid in dentistry - a review". Journal of Evolution of Medical and Dental Sciences 2013; Vol2, Issue 37, September 16; Page: 7077-7083.

\begin{abstract}
Coined by Dr. John Scheel, Henry Lindlahr crediting him as "father of Naturopathy", Naturopathy system of Medicine is a system of healing science stimulating the body's inherent power to regain health with the help of five great elements of nature. Naturopathy provides not only a simple practical approach to the management of disease, but a firm theoretical basic which is applicable to all holistic medical care and by giving attention to the foundations of health; also offers a more economical frame work for the medicine of future generation. Naturopathy is an approach to healing using "natural" means such as diet and lifestyle. For treatment, it primarily stresses on correcting all the factors involved and allowing the body to recover itself. In dentistry, various modalities are available therefore, supporting dental treatment. For the same purpose, this paper is intended to have an overview of other dental treatment modalities available via i.e. Naturotherapy.
\end{abstract}

KEYWORDS: Nature therapy, hydrotherapy, therapeutics.

INTRODUCTION: Naturopathy system of Medicine is a system of healing science stimulating the body's inherent power to regain health with the help of five great elements of nature- Earth, Water, Air, Fire and Ether. Naturopathy is a call to "Return to Nature" and to resort to simple way of living in harmony with the self, society and environment. 1

Naturopathy provides not only a simple practical approach to the management of disease, but a firm theoretical basic which is applicable to all holistic medical care and by giving attention to the foundations of health; also offers a more economical frame work for the medicine of future generation. ${ }^{2}$

Naturopathy is an approach to healing using "natural" means such as diet and lifestyle. Naturopathy may incorporate approaches such as dietary supplements, herbs, exercise, massage, iridology, acupuncture, hair analysis and homeopathy. Although it has some basic themes, there is no unified theory and set of practices; individual practitioners select approaches which appeal to them and which seem to work with their patients. ${ }^{6}$

Though the basic Nature Cure deals only with Pancha Mahabhootas, the recent developments advocates the practice of drugless therapies like Massage, Electrotherapy, Physiotherapy, Acupuncture and Acupressure, Magneto-therapy etc. Diet plays a major role, above all. 6

DEFINITION2: Dorland's Illustrated Medical Dictionary defines Naturopathy as "a drugless system of therapy, making use of physical forces such as air, light, water, heat, message, etc.

HISTORY5 ${ }^{5}$ The roots of naturopathy can be traced back to the teachings of Hippocrates, Galen and Paracelsus, but many of its healing traditions are derived from religious tradition, folk and Native 
American medicine. Healing took many forms from the herbal medicine and Shaman rituals of the Native Americans to the mercury purges and bloodletting of the allopathic practitioners, each giving rise to systems of medicine which would compete with one another over the next century. To this was added the folk medicine traditions the large European immigration of the late 19th and early 20 th centuries brought with it. Due to this, Naturopathy system of medicine was arrived in $20^{\text {th }}$ century.

Naturopathy was brought to the United States in 1896 by Dr. Benedict Lust, who set up the first college and sanitarium in New York City. He began teaching the Kneipp Water Cure which was popular in Europe. Dr. Lust established the Kneipp Water-Cure Institute in New York City, which later began teaching the use of diet, nutrition, light therapy, spinal manipulation, homeopathy and herbal medicine.

Nature Cure movement started in Germany \& other western countries with "Water cure" (Hydrotherapy). Water cure was synonymous with Nature Cure in those early days. The credit of making Water cure word famous goes to Vincent Priessnitz (1799-1851) who was a farmer. Dr. Henry Lindlahr and others go to the extent of crediting him as "father of Naturopathy". The word "Naturopathy" has been coined by Dr. John Scheel in the year 1895 and was propagated and popularised in the western world by Dr. Benedict Lust. They were the first of numerous naturopathic medical schools which were to spring up over the next few decades. From this beginning, the ideas, philosophy and medicine spread until naturopathic medicine was on the leading edge of the nature cure movement of the early and middle 20th century.

A number of Doctors of modern medicine and others became Nature Cure enthusiasts and gradually added a number of modalities within the fold of Naturopathy and scientifically developed them. Nature Cure movement gained momentum in India as Mahatma Gandhi, "Father of the Nation" became much interested in this system and included it in his programmes. He had also established a Nature Cure Hospital in Uruli Kanchan, Dist. Poona, State Maharashtra which is still functioning.

\section{BASIC CONCEPTS OF NATUROPATHY SYSTEM OF MEDICINE: 2, 7}

Nature Cure is a way of life of which we find a number of references in the Vedas and other ancient texts. The morbid matter theory, concept of Vital force and other concepts upon which Nature Cure is based are already available in old texts which indicate that these methods were widely practiced in ancient India.

The whole practice of Nature cure based on the following three principles:

- Accumulation of morbid matter

- Abnormal composition of blood and lymph

- Lowered vitality

Nature Cure Believes that all the disease arises due to accumulation of morbid matter in the body and if scope is given for its removal, it provides cure or relief. The fundamental difference in Nature Cure with other systems is that its theory and practice are based on holistic view point whereas the latter's approach is specific. Nature Cure does not believe in the specific cause of disease and its specific treatment but takes into account the totality of factors responsible for diseases such as one's un-natural habits in living, thinking, working, sleeping, relaxation, sexual indulgence etc, and also considers the environmental factors involved which on the whole disturbs the normal functioning of the body and lead it to a morbid, weak and toxic state. 
For treatment, it primarily stresses on correcting all the factors involved and allowing the body to recover itself. A Nature Cure physician helps in Nature's effort to overcome disease by applying correct natural modalities and controlling the natural forces to work within safe limits. The five main modalities of treatment are air, water, heat, mud and space.

\section{PRINCIPLES OF NATUROPATHY SYSTEM OF MEDICINE: 1}

1. All disease, their cause and their treatment are one.

2. The basic cause of disease is not bacteria. Bacteria develop after the accumulation of morbid matter when a favorable atmosphere for their growth develops in body. Basic cause is morbid matter, not the bacteria.

3. Acute diseases are our friends not enemies. Chronic diseases are the outcome of wrong treatment and suppression of the acute diseases.

4. Nature is the greatest healer. Body has the capacity to prevent itself from diseases and regain health if unhealthy.

5. In Naturopathy patient is treated and not the disease.

6. In Naturopathy diagnosis is easily possible. Ostentation is not required. Long waiting for diagnosis is not required for treatment.

7. Patients suffering from chronic ailments are also treated successfully in comparatively less time in Naturopathy.

8. After emerging, suppressed disease can be cured by Naturopathy.

9. Nature Cure treats physical, mental, social (moral) and spiritual all four aspects at the same time.

10. Nature Cure treats body as a whole instead of giving treatment to each organ separately.

11. Naturopathy does not use medicines. According to Naturopathy "Food is Medicine".

12. Doing prayer according to one's spiritual faith is an important part of treatment.

In short, Nature Cure includes all the available non-invasive treatments and diagnostic modalities which do not interfere with the body's natural functional capacity and healing process and are in affirmity with Nature's constructive Principles.

\section{DIAGNOSTIC METHODS OF NATUROPATHY SYSTEM OF MEDICINE: 1}

Naturopathy adopts the following diagnostic methods

- Full life case history- covering all the facts of life since birth.

- Facial Diagnosis-the science of facial expressions by studying the various characteristic features in the body.

- Iris Diagnosis- study of Iris indicating the condition of various visceral organs.

- Modern clinical diagnosis to some extent.

\section{TREATMENT MODALITIES UNDER NATUROPATHY SYSTEM OF MEDICINE 1}

The methods applied for cure in Naturopathy are the following:-

1. Water Therapy: Water is the most ancient of all the remedial agents. It is employed in different forms in treatment and produces several types of physiological effects depending upon temperature and duration. Hydrotherapy is employed in almost all types of disease conditions. 
2. Air Therapy: Fresh air is essential for good health. Air therapy is employed in different pressures and temperatures in variety of disease conditions.

3. Fire Therapy: Existence of all the creatures and forms depend upon "Agni" (Fire). In nature Cure treatment, different temperatures are employed through different heating techniques to produce different specific effects.

4. Space Therapy: Congestion causes disease. Fasting is the best therapy to relieve congestions of body and mind.

5. Mud Therapy: Mud absorbs, dissolves and eliminates the toxins and rejuvenates the body. It is employed in treatment of various diseases like constipation, skin diseases etc.

6. Food Therapy: Most of the diseases are amenable through food therapy. As you eat so will you be physically fit as well as mentally. Your food is your medicine. These are the main slogans of Nature Cure.

7. Massage Therapy: Massage is a generally employed for tonic, stimulant and sedative effects. It is an effective substitute for exercise.

8. Acupressure: There are different points of hands, feet and body which are associated with different organs. By applying pressure on these selected, related organs can be influenced for getting rid of their ailments.

9. Magneto Therapy: Magnets influence health; South and North poles of different powers and shapes are employed in treatment, by applying directly on different parts of the body or through charged up water or oil.

10. Chromo Therapy: Sun rays have seven colors -violet, indigo, blue, green, yellow, orange and red. These colors are employed through irradiation or body or by administrating charged motor, oil and pills for treatment.

\section{NATUROPATHY AND DENTISTRY: ${ }^{3,8}$}

Naturopathic medicine focuses on restoring the body back to health by supporting and strengthening the natural healing properties found internally. Naturopathic medicine, including naturopathic dentistry, looks to nontoxic, safe materials for supplemental healing support. At its core, naturopathic medicine and naturopathic dentistry believe that the overall health of the body affects the health of the mouth, and oral health affects the health of the body. The American Dental Association (ADA) agrees. In a recent paper the ADA stated: "Oral health is not separate from overall health; in fact, oral health is often associated with other conditions, including stroke, heart disease and diabetes. Perhaps it is because most of us see a dentist for oral health care and a general physician or family doctor for overall care that we separate the health of our mouth from the rest of our body." Both traditional medical practitioners and holistic, naturopathic practitioners agree the endocrine, immune, cardiovascular, and dental systems are related.

In general, naturopathic dentistry looks for nontoxic, non-metal solutions to increase oral health and promote good oral hygiene. While naturopathic dentists provide conventional services, like examinations and cleanings, treatment for gingivitis and gum diseases, fillings, crowns, and bridges, they may also look at issues around TMJ, snoring and sleep apnea, and halitosis. Many naturopathic dentists may conduct a through blood work panel, screening for allegoric reactions or lower tolerance to the ingredients found in fillings, bridges, and crowns. Some naturopathic dentists prefer not to perform root canals, as they believe the bacteria can never been fully cleaned from the 
canal. Most dentists, both conventional and naturopathic avoid mercury in fillings. This is a standard, but a fairly new convention that began in the naturopathic dentistry movement.

Conventional dentists may not offer alternatives to traditional fillings and materials. Naturopathic dentists may take the time to test for the biocompatibility of the materials they are using. Naturopathic dentists believe that even if they are not ingested, some materials may have an ill effect on their patients overall health. A body's reaction to different materials will determine which composites are used in treatment.

Some non-traditional techniques may consist of EDS (Electro Dermal Screening), Applied Kinesiology (testing utilizing muscles or other indicators), CRA (Contact Reflex Analysis), NET (to counter emotional blocks), NAET (to counter allergens), hypnosis, herbs, essentials oils, magnets, homeopathy, heat and cold, light therapy, colour therapy, massage, cranio-sacral manipulation, hydrotherapy and aroma therapy. Some of these modalities are used routinely in "traditional" dental offices, for example hypnosis for pain control, kinesiology for materials and bite testing and craniosacral manipulation for treatment of TMJ-related structural problems. A conscientious dentist must continue to pursue excellence in dental procedures and technology. Likewise, all health professionals who want to do the best for their clients are duty-bound to keep abreast of all that is available through that profession. Throwing Naturopathy into the mix compounds the duty but enhances the service.

One aspect of dentistry from a Naturopathic perspective: Essential oils. Essential oils may be associated with aroma therapy and herbal preparations.

Essential oils are more concentrated and highly refined versions of 'fragrances' used in aroma therapy and some perfumes and cosmetics. Tinctures are extracts of herbs drawn usually in alcohol or vinegar.

A drop of Rose oil on the pillowcase can help to increase trust and confidence. It is good for apprehensive new patients but will not overcome attitudes, brashness or inappropriate chair side effects. A mixture of 1/3 Peppermint oil, 2/3 ethanol (95\% grain alcohol -Ever clear) is great for headaches. A drop placed on and rubbed into the middle of the forehead and temples will diminish most headaches within 90 seconds. Additional drops placed on the occipital and /or the mastoid processes also help. The headache might not go away, but it definitely decreases in severity.

Peppermint is emotionally, physically and mentally invigorating. Lavender rubbed into 'trigger pains' or muscle "knots" helps relax the muscle and assist lymphatic drainage. It is good for sprains, burns, mouth abscesses, skin conditions and helps prevent scarring. It works well applied directly on the area of concern.

Lemon is antiseptic and anti-viral. It is used as an astringent. It helps purify water (a few drops per glass) and air (through a diffuser). It helps clean skin, for it removes gum, oil, and grease. It is mentally refreshing.

Clove oil (eugenol) is sedative for toothaches. Myrrh, Rose, Frankincense and Lavender are useful for gingivitis and periodontal infections. Helichrysum applied with a Q-tip every 15 minutes after periodontal (gum) surgery will help decrease the pain. Tooth decay and periodontitis (gum disease) must be addressed professionally, and there is no substitute for immaculate oral hygiene. Clean teeth do not decay and healthy gums do not bleed, have pockets, collect plaque or generate bad breath. 
Most naturopathic dentists dissuade the use of fluoride, in mouthwash, drinking water, and toothpaste. Ingested fluoride, some research suggests, has been linked to cancer and bone issues. Other research suggests there is no real benefit from fluoride, so many naturopathic dentists opt to stay away from it. Conventional toothpastes may contain harsh abrasives, including propylene glycol. Natural toothpastes and mouthwashes are becoming more popular alternatives for oral health, hygiene and maintenance. In these products, you are apt to find:

- Baking soda, sea salt, citrus acid to fight tartar

- Green tea oil and peppermint oil to fight bacteria

- Zinc oxide, papaya plant extract to whiten teeth

- Grapefruit seed extract to block acids

Some of these holistic products may also be gluten free and low in sulfates or sulfate free for consumers with allergies or sensitivities.

CONCLUSION: Treatment by a "naturopathic" or "holistic" or "natural" or "biological" dentist is no less expensive than conventional treatment. Fees may even be higher because of the additional time, skill, care and judgment involved. This treatment is also no less demanding of the patient for conscientious follow-up with home care and periodic visits for preventive and maintenance appointments.

Any dentist (any health professional) should be willing and able to offer scientific rational for everything he or she does. Be willing to pay for the extra time if many questions are asked.

Overall, naturopathic dentists believe that healthy teeth and gums are reflective of a healthy body, and vice versa. Naturopathic dentistry will treat the symptoms of unhealthy teeth but also look to identify and then treat the cause of the affliction.

Authors contribution: Author $1^{\text {st }}$ and $2^{\text {nd }}$ has done extensive review and formulated while $3^{\text {rd }}$ author has reformulated \& corrected.

\section{REFERENCES:}

1. Available from: www.indianmedicine.nic.in/html/naturopathy.htm[cited on March 18 2013]

2. Available from: http://unpan1.un.org/intradoc/groups/public/documents/APCITY/UNPAN009845.pdf [cited on April 16 2013]

3. Available from: http://www.svcole.com [cited on April 21 2013]

4. Available from: http://nccam.nih.gov/health/naturopathy/D372.pdf [cited on April 30 2013]

5. Available from: http://www.rockwoodnaturalmedicine.com/pdf/HISTORY\%200F\%20NATUROPATHIC\%20 MEDICINE.pdf [cited on May 21 2013]

6. Available from: http://kcahf.org/content/ISNat.pdf. [Cited on May 26 2013]

7. Available from: http://lifewithayurveda.blogspot.in/2007_02_01_archive.html. [Cited on September 10 2013].

8. Available from: http://blog.dentisseprofessionals.com/blog/bid/243264/NaturopathicDentistry. [cited on September 10, 2013] 


\section{REVIEW ARTICLE}

\section{AUTHORS:}

1. Yatish Kumar Sanadhya

2. Sanadhya Sudhanshu

3. Sorabh R. Jain

4. Nidhi Sharma

\section{PARTICULARS OF CONTRIBUTORS:}

1. Associate Professor, Department of Medicine, SRG Hospital and Medical College, Jhalawar.

2. Assistant Professor, Department of Public Health Dentistry, RUHS College of Dental Sciences, Shastri Nagar, Jaipur.

3. Post Graduate Student, Department of Prosthodontics, Pacific Dental College and Hospital, Debari, Udaipur.
4. Junior Lecturer, Department of Periodontics, Jaipur.

\section{NAME ADDRESS EMAIL ID OF THE} CORRESPONDING AUTHOR:

Dr. Sanadhya Sudhanshu, Assistant Professor,

Department of Public Health Dentistry, RUHS College of Dental Sciences, Shastri Nagar, Jaipur.

Email-drsudhanshupcd@gmail.com

Date of Submission: 29/08/2013.

Date of Peer Review: 30/08/2013.

Date of Acceptance: 10/09/2013.

Date of Publishing: 11/09/2013 